\title{
Correlation between saliva iga level and T cell CD4+ in HIV/AIDS patients
}

\author{
Irna Sufiawati*, Harum Sasanti**, Samsuridjal Djauzi** \\ * Department of Oral Medicine Faculty of Dentistry Universitas Padjadjaran \\ ** Department of Oral Medicine Faculty of Dentistry Universitas Indonesia
}

\section{ABSTRACT}

Background: HIV infection appears to have direct effects on oral mucosal immunity, cellular and humoral. Antibody secretion, especially salivary immunoglobulin A ( $\lg A)$, is a useful indicator of mucosal immune function. This immune system component is recognized as an important first-line of defense against pathogens which colonize and invade mucosal surfaces in the oral cavity. Objectives: The purpose of this study was to investigate salivary IgA levels and to determine its correlation with CD4+ T-cell counts among HIV-infected patients in Pokdisus AIDS Cipto Mangunkusomo Hospital Jakarta. Methods: The design study was using a cross-sectional study. Whole paraffin-wax-stimulated saliva was collected from 103 HIV-infected patients and 30 healthy individuals. Saliva was collected using the spitting method. Salivary IgA levels were determined by the immunoturbidimetry method using the Behring Turbitimer Analyser. CD4+ T-cell counts was analyzed by flowcytometri. Results: Salivary lgA levels were $141.55 \pm$ 83.23 (HIV group) and $97.24 \pm 38.25$ (healthy individuals). The Mann-Whitney U test showed salivary IgA levels were significantly higher in HIV/AIDS subjects compared with healthy individuals $(p<0.1)$. Most of the subject have severe immunosuppresion with CD4+ T-cell counts $<200$ cell $/ \mathrm{mm}$. ${ }^{3}$ Pearson's correlation test between CD4+ T-cell counts and salivary lgA levels showed no significant correlation $(r=0.06, p>0.1)$. Conclusion: This study indicates that total salivary IgA levels were significantly higher in the HIV-infected patients compared to control, and salivary lgA level seem not to be related significantly to CD4+ T-cell counts.

Key words: Salivary IgA, CD4+ T cell, HIV/AIDS.

\section{INTRODUCTION}

Since the beginning of theHIVepidemic, many researchers have proven that HIV infection affects the immune system, both cellular and hummoral imunity, directly. ${ }^{1,2}$ The immunosuppression is marked by reduced $\mathrm{T}$ cell $\mathrm{CD} 4+$. In addition to $\mathrm{T}$ cell $\mathrm{CD} 4+$ as the cellular immune component, the local immune hummoral component immunoglobulin $\mathrm{A}$ $(\operatorname{IgA})$ also plays a role in protection against oral lesions. Immunoglobulin A has an important role as a protector against microorganisms through various kinds of mechanism in the mucosal tissue, including direct killing, agglutination, inhibition of microorganism penetration and adhesion, enzyme and bacterial toxin inactivation, opsonisation and cell-mediated killing.

Former studies have reported that abnormality of saliva IgA level in HIV/AIDS patients is observed ${ }^{1,2,12,13}$, and that there is a relationship 
between the number of T cell CD4+ and salivary IgA level in HIV infection. The results of studies performed by Muller et al, Sweet et al, and Sistig et al. ${ }^{12,15,16}$ show that IgA level in HIV/AIDS patients is lower that HIV-negative group. Challcombe and Sweet ${ }^{1}$ reported that the whole saliva IgA level is lower, both in HIV and AIDS patients, particularly in the advance stage of HIV infection. Grimoud et al. ${ }^{14}$ reported that there is a significant increase in saliva IgA level in HIV patients with CD4+<200.

The change of saliva IgA level in HIV/AIDS patient shown in the above contradictive studies maybe due to factors such as saliva removal technique differences, variation during saliva removal, gland type differences during saliva removal, saliva flow rate, the HIV infection stage of the research population, the number of subject, and/or medications used by the subject.

This study is aimed at discovering the salivary IgA level and its correlation with the number of T cell CD4+ in HIV/AIDS patients at Pokdisus AIDS Cipto Mangunkusumo Hospital, Jakarta.

\section{MATERIALS AND METHODS}

This a cross sectional observational analytical study taken place in Pokdisus AIDS Clinic, Faculty of Medicine, Universitas Indonesia Cipto Mangunkusumo Hospital Jakarta and Oral Disease Clinic, Faculty of Dentistry, Universitas Indonesia, Jakarta, Dec 12, 2006 until March 3, 2007.

The subjects are HIV/AIDS patients Jakarta, who meet the inclusion criteria. HIV-positive diagnosis is confirmed by the Department of Internal Medicine. In order to determine the saliva IgA level reference value for this study, saliva examination was performed to 30 healthy individuals without any systematic and dental-oral disorder with an age range similar to the study subjects.

\section{Saliva sampling and saliva flow measurement}

The saliva sampling performed using spitting method (standard method of Navazesh) ${ }^{17}$ Before and after the process, the subjects were not allowed to eat, drink, and cleaning their mouth for approximately 90 minutes before the sampling and they were also not allowed to talk, move their tongue, or swallow. The subjects were asked to sit down comfortably in as straight position, head down with right hand holding tube to collect the saliva. Collected saliva is the whole saliva with stimulation. The sampling was performed for 5 minutes following wax paravin stimulation. The subjects were instructed to spit the saliva in her/his mouth to the measuring tube through a funnel glass. The saliva flow rate with stimulation is determined. Saliva is immediately stored in the freezer with a temperature of $-70^{\circ} \mathrm{C}$ for IgA level measurement.

\section{Saliva IgA level and number of T cell CD4+ measurement}

The saliva examination to measure IgA level and data collection are performed using turbitimer. Initially, saliva was centrifuged 10'/3000 RPM, and then the supernatant is removed and isolated. After that, 50 micro of supernatant was taken, added with 500 micro IgA reagent (from Boehring), and the result was recorded. The data of $T$ cell CD4+ was analyzed using flowcytometri.

\section{Ethical issue}

An ethical clearance has been given by the Research Ethic Commission of the Faculty of Dentistry, Universitas Indonesia.

\section{RESULTS}

The subjects consist of 103 individuals, i.e. HIV positive patients diagnosed by the Allergic Division of the Department of Internal Medicine, RSUPN-CM who met the inclusion criteria and voluntary participated in the study. There were also 30 Faculty of Dentistry Universitas Indonesia students participated in the research for measuring the saliva IgA level as the reference value.

The subject characteristics can be observed in the following table. The percentage of subjects based on the HIV infection risk can be seen in Fig 1. Most of the HIV infection risk is intravenous drug use (IDU). The result shows that most of the subject has been provided with ARV therapy, as in the Fig. 2.

The illustration of subject immunology status based on the number of serum T cell CD4+ is listed in Tab. 1 below:

Data showing salivary IgA reference value of 30 healthy individuals is presented in Tab. 1 .

The mean difference of Mann-Whitney $U$ 


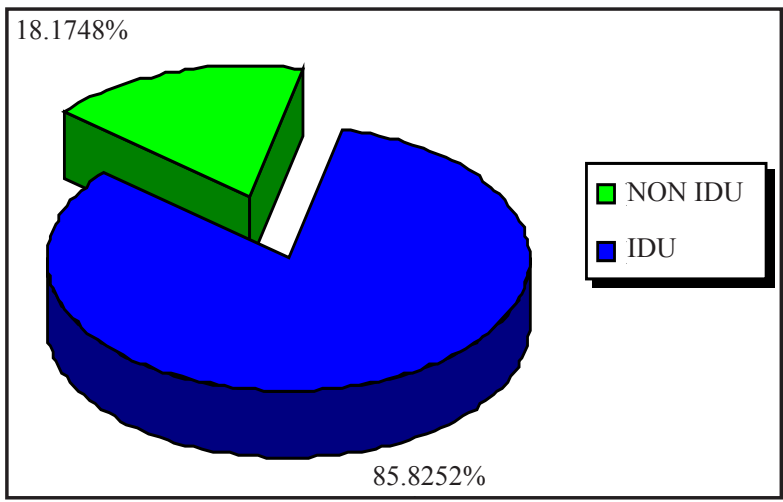

Figure 1. Subject distribution based on HIV infection risk.

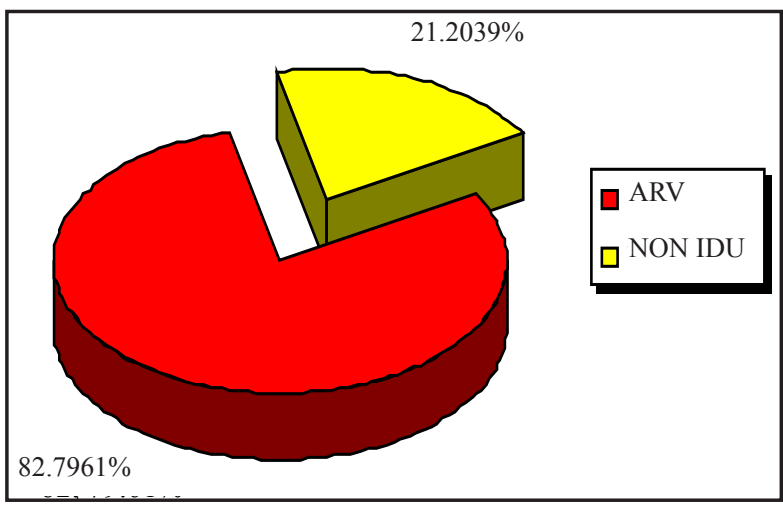

Figure 2. Subject distribution based on the anti-retrovirus therapy.

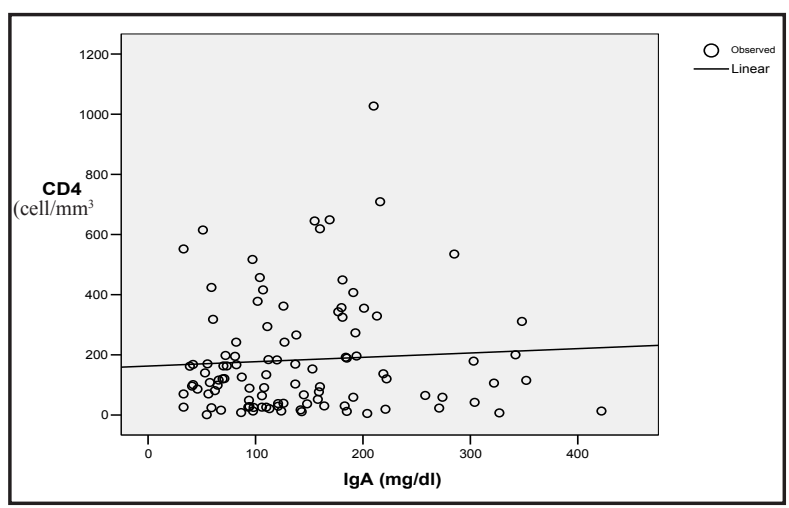

Figure 1. Correlation between the number of T cell CD4+ and salivary IgA level.

(Pearson Correlation Test, $r=0.06$ and $p>0.1$ )

on salivary IgA reference value shows a $p>0.1$. Thereby, there is no significant difference in male and female salivary IgA reference values.

Based on gender, the Mann-Whitney $U$ test result shows no significant proportion difference between salivary IgA level in male and female HIV/AIDS patients $(p>0.1)$.

Based on the difference between salivary
Table1. Subject characteristics based on age and gender $(n=10)$.

\begin{tabular}{lcc}
\hline Characteristic & Total & Percentage (\%) \\
\hline Age (range 20-46, Average & 28.19 & $+4.89)$ \\
20-29 years old & 71 & 68.93 \\
30-39 years old & 29 & 28.15 \\
40-49 years old & 3 & 2.92 \\
Gender & & \\
Male & 89 & 86.41 \\
Female & 14 & 13.59 \\
\hline
\end{tabular}

Table 2. Frequency distribution of T cell CD4+ $(n=103)$.

\begin{tabular}{ccc}
\hline $\begin{array}{c}\text { Number of T Cell CD4+ } \\
\text { (cell//mm })\end{array}$ & Total & $\begin{array}{c}\text { Percentage } \\
\text { (\%) }\end{array}$ \\
\hline$\geq 500$ & 9 & 8.74 \\
$350-499$ & 9 & 8.74 \\
$200-349$ & 11 & 10.68 \\
$<200$ & 74 & 71.85 \\
\hline
\end{tabular}

Table 3. Salivary IgA level reference value $(n=30)$.

\begin{tabular}{lcc}
\hline Gender & N & IgA level $(\mathrm{mg} / \mathrm{dl})$ \\
\hline Male & 13 & $96.30 \pm 38.47$ \\
Female & 17 & $97.76 \pm 39.25$ \\
Average & & $97.24 \pm 38.25$ \\
\hline
\end{tabular}

Table 4. Salivary IgA level in HIV/AIDS.

\begin{tabular}{ccc}
\hline Gender & $\mathrm{N}$ & IgA level $(\mathrm{mg} / \mathrm{dl})$ \\
\hline Male & 89 & $142.08 \pm 84.09$ \\
Female & 14 & $138.23 \pm 80.42$ \\
Average & & $141.55 \pm 83.23$ \\
\hline
\end{tabular}

IgA level in HIV/AIDS patients and salivary lgA level reference value, the Mann-Whitney $U$ test value shows that salivary IgA level in HIV/AIDS patients is significantly higher than healthy individuals $(p<0.1)$.

Correlation between the number of $\mathrm{T}$ cell CD4+ and salivary IgA level is assessed using Pearson correlation test. The result can be seen in the diagram.

The Figure above shows that increased $T$ cell CD4+ number will result in IgA increase. However, the Pearson correlation test result shows that influence between the 2 variables is too small $(\mathrm{t}=0.06)$ and there is no significant difference between them $(p>0.1)$. 


\section{DISCUSSION}

$\mathrm{T}$ cell CD4+ plays important role in the immune system since $\mathrm{T}$ cell CD4+ dysfunction and/or depletion cause immunological defects. Therefore the number of T cell CD4+ represents the HIV/AIDS patient immunological status. The results of the study show that the majority of subjects have $<200 \mathrm{cell} / \mathrm{mm}^{3} \mathrm{~T}$ cell $\mathrm{CD} 4+$, so it can be concluded that most of the subjects is in a severe immunosuppression status. Nevertheless, to determine that subject is in AIDS stage, other data such as accompanying opportunistic infections are needed.

Based on the literature, the AIDS diagnosis depends on accurate clinical and laboratory diagnostics. The CDC definition of AIDS stated that a patient is considered as AIDS when he/she is stated as HIV-positive with $<200$ cell/ $\mathrm{mm}^{3} \mathrm{~T}$ CD4+ or $<$ CD4 + percentage $<14 \%$ of lymphocyte number and/or has one/more opportunistic infections such as pneumocytis carinii pneumonia, mycobacterial, crytococcal, cytomegalovirus, toxoplasma, and tumors such as Kaposi's sarcoma and lymphoma. For developing countries, the World Health Organization (WHO) has developed another definition based on the clinical symptoms that does not need laboratory data on the presence of infection due to the fact that developing countries have limited financial resource for laboratory assays.

In people with competent immune system, the cellular and hummoral immunities are linked to each other and work simultaneously. Therefore, if CD4+ cell deficiency occurrs, the hummoral immunity will be disturbed. So, it is assumed that in HIV/AIDS infected patient, the hummoral immunity level that plays the role in oral environment is also altered.

Salivary IgA level is the main variable in the research to determine changes in the immune system component of HIV/AIDS patients. Before determining salivary IgA level in HIV/AIDS patients, at first the salivary lgA level reference value from healthy individuals is established. A literature stated that the mean of salivary IgA level that mechanically stimulated is $110 \mathrm{mg} /$ dl $(50-170 \mathrm{mg} / \mathrm{dll}) .{ }^{19}$ This value also cannot be considered as the reference value for this study because it is obtained from examination of different ethnic population. It is already known that different ethnic and demography affect the salivary IgA level. Nevertheless, the salivary IgA level reference value obtained in this study shows almost similar value, that is $97.24 \pm 38.25 \mathrm{mg} / \mathrm{dl}$.

The study data show that salivary IgA level in most of the subjects is higher than the reference value. There is no significant proportion difference between men and women. The result is in line with several former studies. Coogan et $\mathrm{al}^{7}$ and Lin $\mathrm{Al}$ et al..$^{20}$ noted a significant salivary lgA concentration increase in HIV patients. Mellanen et al. ${ }^{21}$ also reported a significantly higher level of salivary IgA in all HIV infection phases, except for the asymptomatic phase. The literature mentioned that the IgA level increase in HIV infected patients illustrates that there is a cell $\mathrm{B}$ polyclonal activation in the early stage of HIV infection. Antigenic load increase also has the capability to induce the salivary IgA level increase. The antibody of saliva can be induced through stimulus from intestinal lymphoid by antigen ingestion. This may result in plasma cell precursor IgA release from Payer's patches that migrate through vascular tissue to mucosa tissue such as salivary gland. So, the high level of salivary IgA represents its role in the oral mucosal membrane defense mechanism.

In addition, the data also shows $13.59 \%$ subjects with salivary IgA level below the reference value. The studies performed by Muller et $\mathrm{al}^{13}$, Sweet et $\mathrm{al}^{15}$, and Sistig et al. ${ }^{16}$ Show that IgA level of HIV/AIDS patients is lower than the HIVnegative group. Challcombe \& Sweet ${ }^{1}$ reported that whole saliva IgA concentration is lower both in HIV patients and AIDS patients, and it is more obvious in the advance stage of HIV infection. Lu and Jacobson ${ }^{23}$ also stated that in the early HIV infection stage, the balance between cellular and hummoral immune function can be maintained, but the immune response is disrupted by chronic HIV infection. The HIV infection clinical stage where oral mucosa immunity fails (decreases) is found when opportunistic infections appear (clinical progression in the stage IV of the disease, referred as AIDS). It can be concluded that the salivaty IgA level deficiency illustrates more obvious immunosuppression state.

The change in salivary IgA level of HIV/AIDS patient that is contradictive in various studies maybe attributed to several factors such as saliva 
collecting technique difference, variation on saliva collecting time, gland type difference, saliva flow rate, HIV infection stage of the study population, number of subjects, and/or medications used by the subject. Salivary IgA level change can also be affected by age, gender, hormonal factor, genetic background, psychological and social economic factors, physical activities, nutrition status, and life style. ${ }^{24,25}$ Many of these factors are not observed in this study, so it is not clear whether those factors affect the difference between IgA level found in this study and those found in former studies.

In HIV-infected individuals, T cell CD4+ depletion is related to the loss of immune functions, including salivary IgA as the indicator of oral mucosa immune function. HIV infects cells through its interaction with CD4+ receptor in several types of cells including $\mathrm{T}$ helper/inducer lymphocyte that has important roles in many immunological process, such as induction of IgA response. ${ }^{7} \mathrm{~T}$ helper cell has a different cytokine secretion profile in hummoral immune response, including IgA secretion. ${ }^{26}$ The reduced number of $\mathrm{T}$ cell CD4+ may decrease IgA secretion secondarily, thereby the IgA system is believed as a system that depends very much on the T cell regulation.

The analysis results of this study show no significant correlation between salivary IgA level and the number of T cell CD4+. This finding is in line with the finding of $\mathrm{Wu}$ and Jackson ${ }^{27}$, that shows insignificant correlation between IgA level and the number of T cell CD4+. Whereas Grimoud et al. ${ }^{14}$ reported increased salivary IgA level in HIVpositive patients with $<200$ amount of T cell CD4+. Others literatures stated a significant increase of IgA level only in AIDS Related Complex phase. ${ }^{28}$

In contrast, other literatures reported that the mucosal antibody response is normal in the early stage of HIV infection but decrease in AIDS stage, representing increased immunodeficiency. ${ }^{2}$ Lu and Jacobson ${ }^{23}$ also reported that the HIV infection clinical stage where oral mucosa immunity decreased is the stage where opportunistic infections occur (clinical progression in stage IV, referred as AIDS).

Correlation between salivary IgA level and the number of T cell CD4+ in HIV/AIDS patient in many contradictive study results above may be caused by various factors such as saliva colleting technique difference, variation of time, differences in gland type, saliva flow rate, and HIV infection stage of the study population and the number of subjects.

\section{CONCLUSION}

This study proves that there is a change in one of the hummoral immune system components in oral cavity in some HIV/AIDS patients in RSUPN Dr. Cipto Mangunkusumo Jakarta, where most of the subjects have higher salivary IgA level compared to the reference value. Most of subjects have heavy immunosuppression state with the number of T cell CD4+ $<200 \mathrm{cell} / \mathrm{mm}^{3}$. However, there is no significant correlation between $\mathrm{T}$ cell CD4+ number and salivary IgA level.

\section{REFERENCES}

1. Challacombe SJ, Sweet SP. Oral mucosal immunity and HIV infection: current status. Oral Disease 2002;8:55.

2. Challacombe SJ, Naglik JR. The effects of HIV infection on oral mucosal immunity. Adv Dent Res 2006;19:29-35.

3. Kinane DF, Lappin DF. Clinical, pathological and immunological aspects of periodontal disease. Acta Odontol 2001;59:154-60.

4. Sistig S, Vucicevic-Boras V, Lukac J, Kusic Z. Salivary lgA and IgG subclasses in oral mucosal disease. Oral Disease 2002;8:282-6.

5. Takahashi K, Mooney J, Frandsen EVG, Kinane DF. IgG and IgA subclass mRNA-bearing plasma cells in periodontitis gingival tissue and immunoglobulin levels in the gingival crevicular fluid. Clin Exp Immunol 1997;107:158-65.

6. Kinane DF, Lappin DF, Koulouri O, Buckley A. Humoral immune responsses in periodontal disease may have mucosal and systemic immune features. Clin Exp Immunol 1999;115:534-41.

7. Coogan MM, Simon $P$, Sweet, Challacombe SJ. Immunoglobulin A (IgA), IgA1, and IgA2 antibodies to Candida albicans in whole and parotid saliva in human immunodeficiency virus infection and AIDS. Infect and Immun 1994;62:892-6.

8. Seeman R, Hagewald, Sztankay V, Drews J, Bizhang M, Kage A. Levels of parotid and submandibular/sublingual salivary immunoglobulin $A$ in responsse to experimental 
gingivitis in humans. Clin Oral Invest 2004;8:233-7.

9. Ogawa T, Kusumoto Y, Hamada S, McGhee JR, Kiyono $\mathrm{H}$. Bacteriodes gingivalis-specific serum IgG and IgA subclass antibodies in periodontal disease. Clin Exp Immunol 1990;82:318-325.

10. Marcotte H, Lavoie MC. Oral microbial ecology and the role of salivary immunoglobulin $A$. Microbiology and Molecular Biol Rev 1998. p. 71-109.

11. Ebersole JL, Cappelli D, Steffen MJ. Charateristics and utilization of antibody measurements in clinical studies of periodontal disease. J Periodontol 1992;63:1110-6.

12. Sistig S, Vucicevic-Boras V, Lukac J, Kusic Z. Salivary IgA and IgG subclasses in HIV Positive patients. EurJ Med Res 2003;8:543-8.

13. Challacombe SJ, Greenspan JS, Greenspan $D$, Dodd C. Salivary IgA subclass responsses in hiv-associated salivary gland disease (in oral manifestations of HIV infection). Chicago: Quintessence; 1995. p.152-8.

14. Grimoud AM, Arnaud C, Dellamonica P, Lodter JP. Salivary defence factor concentrations in relation to oral and general parameters in HIV positive patients. Eur J Oral Sci 1998;106:97985.

15. Muller F, Froland SS, Hvatum M, Radl J, Brandtzaeg P. Both IgA subclasses are reduced in parotid saliva from patients with AIDS. Clin Exp Immunol 1991;83:203-9.

16. Sweet SP, Rahman D, Challacombe SJ. IgA subclasses in HIV disease: dichotomy between raised levels in serum and decreased secretion rates in saliva. Immunol 1995;86:556-9.

17. Navazesh M. Methods for collecting saliva. Ann NY Acad Sci 1993;694(1):72-7.

18. Hoffmann, Rockstroh, Kamps. HIV Medicine 2006. Paris: Flying Pub; 2006. p. 23-94.

19. Amerongen AVN. Ludah dan kelenjar ludah. Arti bagi kesehatan gigi. Yogyakarta: Gadjah
Mada University Press; 1988. p. 84.

20. Lin AL, Johnson DA, Stephan KT, Yeh CK. Saliva composition and flow rates are impacted by early HIV disease irrespective of xerostomic medications. J Evid base Dent Pract 2004;4:246-8.

21. Mellanen L, Sorsa T, Lähdevirta J, Helenius $M$, Kari K, Meurman JH. Salivary albumin, total protein, IgA, IgG and IgM concentrations and occurrence of some periodontopathogens in HIV-infected patients: A 2-year follow-up study. J Oral Pathol Med 2001;30(9):553-9.

22. Steinsvoll S, Myint M, Odden K, Berild D, Schenk K. Reduced serum IgG reactivities with bacteria from dental plaque in HIV-infected persons with periodontitis. J Periodontol 1997;24:823-9.

23. Lu FX, Jacobson RS. Oral Mucosal Immunity and HIV/SIV Infection. J Dent Res 2007;86(3):21626.

24. Marcotte H, Lavoie MC. Oral microbial ecology and the role of salivary immunoglobulin A. Microbiology and Molecular Biology Review 1998. p. 71-109.

25. Bennet KR, Read PC. Salivary immunoglobulin A levels in normal subjects, tobacco smokers, and patients with minor aphtous ulceration. Oral Surg Oral Med Oral Pathol 1982;53:4615.

26. Walker DM. Oral mucosal immunology: An overview. Ann Acad Med Singapore 2004;33(Suppl):27-30S.

27. Wu X, Jackson S. Plasma and salivary IgA sub classes and IgM in HIV-1-infected individuals. $\mathrm{J}$ Clin Immunol 2002;22(2):106-15.

28. Mellanen L, Sorsa T, Lähdevirta J, Helenius M, Kari K, Meurman JH. Salivary albumin, total protein, IgA, IgG and IgM concentrations and occurrence of some periodontopathogens in HIV-infected patients: A 2-year follow-up study. J Oral Pathol Med 2001;30(9):553-9. 